\section{Adrenocorticotropic Hormone}

David J. Libon

Departments of Geriatrics, Gerontology, and Psychology, Rowan University, New Jersey Institute for Successful Aging, School of Osteopathic Medicine, Stratford, NJ, USA

\section{Definition}

Adrenocorticotropic hormone (ACTH) is produced by the anterior pituitary gland and is a component of the hypothalamic-pituitary-adrenal axis. The release of ACTH is associated with the biological response to stress. The production of ACTH from the pituitary gland stimulates the adrenal glands to produce cortisol. The ACTH stimulation test is a common procedure used to assess the integrity of the adrenal glands. This test is used to identify a number of medical conditions including adrenal insufficiency, Addison's disease, and related medical conditions (Melmed and Kleinberg 2008).

\section{Cross-References}

Hypothalamus

\section{References and Reading}

Melmed, S., \& Kleinberg, D. (2008). Anterior pituitary. In H. M. Kronenberg, S. Melmed, K. S. Polonsky, \& P. R. Larsen (Eds.), Williams textbook of endocrinology (11th ed.). Philadelphia: Saunders Elsevier. 